\title{
Prof. Dra. Layla Dawood
}

InterAção - Após 5 anos da defesa de sua Tese, como você percebe a polaridade do sistema internacional, atualmente?

Layla Dawood - Minha tese de doutoramento intitulada "China versus the United States: is bipolarity back? A study of internal balancing as a possible source of international systemic change" ${ }^{1}$, defendida em março de 2013, sob orientação dos professores William Wohlforth (Dartmouth College) e João Pontes Nogueira (PUC-Rio) - buscou identificar possíveis mudanças na polaridade do sistema internacional inaugurado com o fim da Guerra Fria. A tese partiu da hipótese de que o crescimento econômico chinês e, especialmente, os esforços de modernização das forças armadas chinesas caracterizavam um comportamento de balanceamento interno por parte da China, resultando na transformação da estrutura unipolar em bipolar.

Não obstante, a referida hipótese foi apenas parcialmente comprovada: por um lado, verificou-se que o comportamento chinês poderia ser positivamente classificado como balanceamento interno; por outro lado, os esforços chineses ainda não eram suficientes para produzir como resultado a bipolaridade sistêmica. Em outras palavras, o balanceamento interno empreendido pela China ainda se mostrava pouco efetivo na produção de mu- danças na estrutura internacional contemporânea. Neste ponto, algumas ponderações se fazem necessárias: o fundador do Realismo Estrutural, Kenneth Waltz ${ }^{2}$, indicou que, para figurar como polo no sistema, um Estado deveria pontuar bem em todos os recursos de poder; notadamente, econômico, tecnológico e militar. Contudo, a contagem do número de polos no sistema internacional não é uma tarefa trivial. O próprio Waltz falhou em apresentar critérios claros para a identificação empírica de um polo.

De modo a lidar com essa dificuldade, a tese partiu de alguns entendimentos, a saber: 1) o poder econômico e a capacidade política (que remete ao direcionamento dos frutos do crescimento econômico para as finalidades públicas) são essenciais na caracterização de um Estado como polo; 2) contudo, o crescimento econômico deve ser acompanhado de um crescimento militar suficiente para fornecer ao polo ascendente/desafiante chances consideráveis de sucesso numa eventual grande guerra contra o polo estabelecido; 3 ) por grande guerra entende-se um confronto no qual estão em jogo objetivos considerados vitais por ambas as partes (polo ascendente e polo estabelecido) e em que, consequentemente, o uso da totalidade dos recursos de poder é contemplado pelos beligerantes.

Até 2013, com base em dados provenientes

\footnotetext{
${ }^{1}$ DAWOOD, L. I. A. (2013). China versus the United States: is bipolarity back? A study of internal balancing as a possible source of international systemic change. Tese (Doutorado em Relações Internacionais)-Pontifícia Universidade Católica do Rio de Janeiro, Rio de Janeiro.

${ }^{2}$ WALTZ, Kenneth N. Theory of international politics. New York: McGraw-Hill, 1979
} 
de centros de inteligência internacionais e em análises de especialistas em estudos estratégicos, concluímos que os esforços chineses conferiram a esse país alguma expectativa de sucesso em um eventual conflito com os EUA, desde que o mesmo fosse travado nas proximidades de Taiwan. No entanto, os esforços chineses ainda não resultavam em chances consideráveis de sucesso na eventualidade de um conflito travado em águas distantes. Em outras palavras, a China ainda possuía graves problemas relacionados à projeção de poder.

Nos últimos 6 anos, a ascensão econômica e os esforços de modernização das forças armadas chinesas foram mantidos e, em muitos casos, aprofundados. Na arena econômica, a China lançou a chamada "Belt and Road Initiative" (BRI), que compreende uma série de acordos com diversos países do globo voltados à concretização de projetos de infraestrutura, que contribuirão para manter (e possivelmente aumentar) os fluxos comerciais chineses. Se levados a efeito, tais acordos trarão benefícios econômicos à China, ao mesmo tempo em que incrementarão a influência global desse país.

$\mathrm{Na}$ arena militar, a China tem tentado resolver suas deficiências relacionadas à projeção de poder. Nesse sentido, de acordo com um documento produzido pelo Departamento de Defesa estadunidense:

[...] as China's global footprint and international interests have grown, its military modernization program has become more focused on investments and infrastructure to support a range of missions beyond China's periphery, including power projection, sea lane security, counterpiracy, peacekeeping, humanitarian assistance/disaster relief (HA) DR), and noncombatant evacuation operations. In August 2017, China officially opened its first overseas military base in Djibouti, deploying a company of marines and equipment to the base. China likely will seek to establish additional military logistics facilities in countries with which it has longstanding, friendly relationships (SECRETARY OF DEFENSE, 2018, p. II) ${ }^{3}$

A despeito desses esforços chineses mais recentes, os EUA ainda possuem capacidades de projeção de poder imensamente superiores às capacidades da China. A superioridade estadunidense é caracterizada, principalmente, pela posse de um número significativo de submarinos nucleares, porta-aviões, capacidades voltadas ao desembarque anfíbio e aeronaves de última geração.

Sendo assim, acredito que a conclusão da tese permanece atual: a ascensão econômica chinesa e os esforços de modernização das forças armadas caracterizam um processo de balanceamento interno, mas esse ainda não logrou transformar a estrutura do sistema internacional, que permanece unipolar.

\section{IA - Como estratégias de balanceamento interno podem mudar a polaridade do sistema? Por que esta via de estudo contribui com uma lacuna no estudo das Teorias de Relações Internacionais?}

LD - Minha tese buscou dialogar com um conjunto de trabalhos realizados na primeira década dos anos 2000, sob a coordenação do Professor William Wohlforth, que objetivavam testar empiricamente a teoria da balança de poder ${ }^{4}$. Tais testes afirmaram que, em vários exemplos históricos, o balanceamento não logrou transformar sistemas internacionais unipolares, concluindo, assim, que esse comportamento não poderia ser caracterizado como um mecanismo de transformação internacional. Wohlforth et all (2007) defenderam que unipolos (ou hegêmonas) decaem por fenômenos

\footnotetext{
${ }^{3}$ SECRETARY OF DEFENSE. Military and Security Developments Involving the People's Republic of China 2018. Annual Report to Congress.16 Maio 2018. Disponível em: https://media.defense.gov/2018/Aug/16/2001955282/-1/-1/1/2018-CHINA-MILITARY-POWER-REPORT.PDF. Acesso em 11 jan. 2019.

${ }^{4}$ Para maiores informações, ver: WOHLFORTH, W. C. et al.Testing balance of power theory in world history. European Journal of International Relations, v. 13, n. 2, p. 155-185, 2007.
} 
relacionados à super-extensão imperial (gastos demasiados com defesa e consequente perda de dinamismo econômico) e/ou pela intervenção de atores externos aos sistemas (no caso de sistemas históricos anteriores ao atual sistema globalizado).

Creio que os supracitados testes foram bastante convincentes no que se refere ao balanceamento externo, a saber: historicamente, a formação de alianças contrárias ao unipolo não se mostrou capaz de produzir a queda hegemônica e a consequente mudança de sistemas unipolares. No entanto, a meu ver, a inefetividade do balanceamento interno na produção da mudança internacional não havia sido comprovada empiricamente.

Nesse sentido, defendo o argumento de que a teoria da balança de poder pode explicar o equilíbrio (e, portanto, a continuidade sistêmica), mas também pode ser pensada como uma explicação realista para a mudança estrutural. Isso porque o balanceamento interno, quando bem sucedido, acarreta a ascensão de novos polos, potenci- almente transformando sistemas unipolares em bipolares ou sistemas bipolares em multipolares. Em outras palavras, argumento que uma teoria realista da mudança internacional estaria, necessariamente, conectada ao fenômeno do balanceamento interno.

Para aprofundar esse argumento, desenvolvi um modelo teórico com vistas a caracterizar o fenômeno do balanceamento interno e permitir o teste empírico da sua ocorrência, bem como de suas consequências para a polaridade sistêmica. A meu ver, o balanceamento interno pode ser definido como um processo composto por um conjunto de ações estatais que, com o passar dos anos, possui o potencial de reduzir o gap de capacidades entre o(s) polo(s) ascendentes e o(s) polo(s) estabelecidos. Tais ações remetem ao incremento da riqueza de um país, bem como à emulação e a inovação militar. O quadro abaixo resume as atividades que, a meu ver, caracterizam o processo de balanceamento interno: ${ }^{5}$

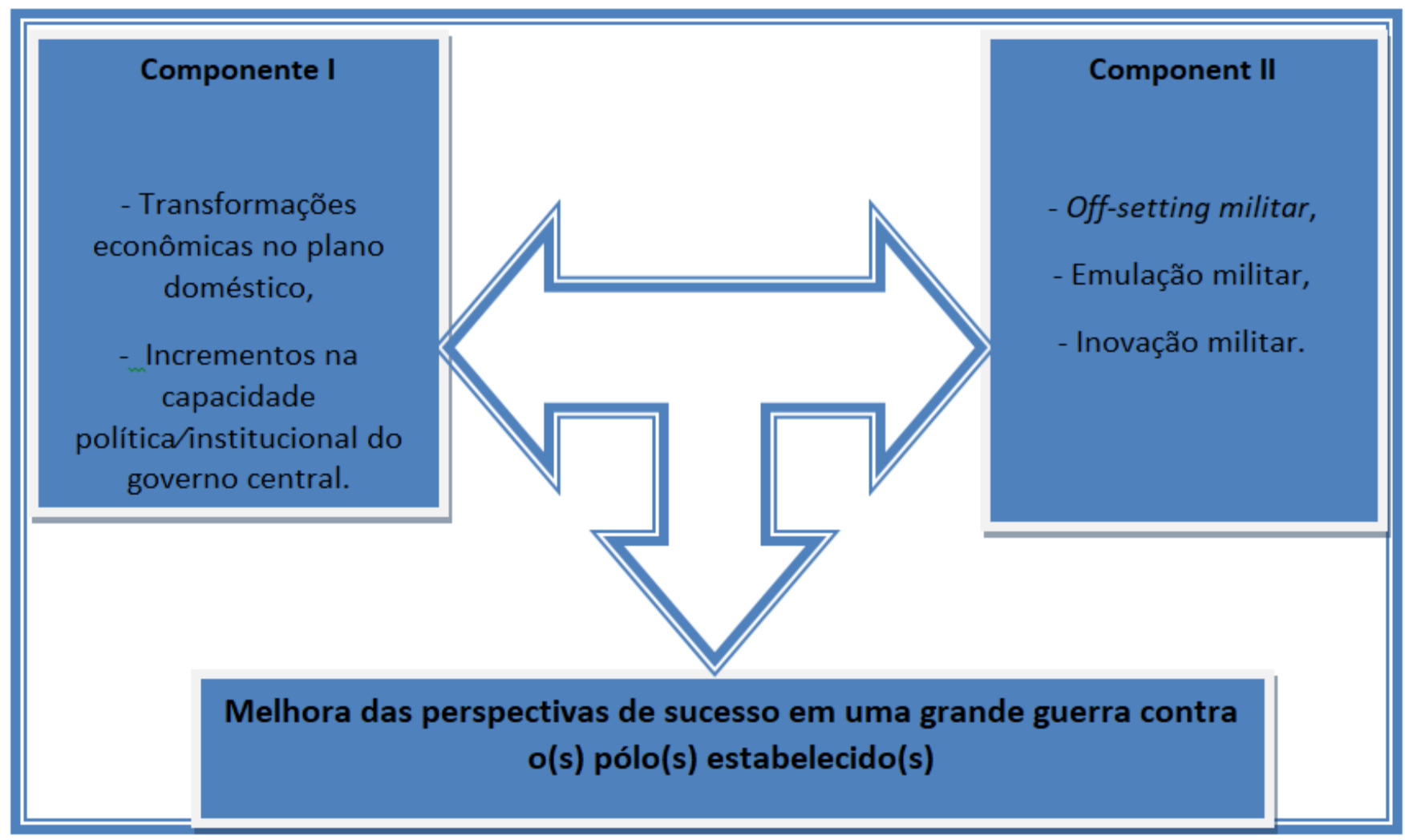

${ }^{5}$ DAWOOD, L. I. A. (2013). China Versus the United States: is bipolarity back? A study of internal balancing as a possible source of international systemic change. Tese (Doutorado em Relações Internacionais)-Pontifícia Universidade Católica do Rio de Janeiro, Rio de Janeiro, cap. 3. 
Para avaliar empiricamente a ocorrência desse processo, é necessário comparar as capacidades do(s) polo(s) ascendente(s) em relação ao(s) polo(s) estabelecido(s). O balanceamento interno está relacionado àquelas atividades que permitem que polos desafiantes lidem com as capacidades de polos estabelecidos na eventualidade de uma grande guerra.

IA - Na atual conjuntura internacional, a China pode ser classificada como o maior Challenger à primazia americana no sistema internacional? Já podemos definir que estamos próximos de um cenário de bipolaridade conflituosa?

LD - A National Security Strategy publicada pela administração do presidente estadunidense Donald Trump em dezembro de $2017^{6}$ adotou um tom incisivo na identificação de ameaças internacionais, afirmando que a China e a Rússia desafiam o poder dos EUA. Isso parece denotar que os desafios apresentados por esses países são percebidos pela atual administração dos EUA como equivalentes:

\begin{abstract}
China and Russia challenge American power, influence, and interests, attempting to erode American security and prosperity. They are determined to make economies less free and less fair, to grow their militaries, and to control information and data to repress their societies and expand their influence (NSS, 2017, p.2)
\end{abstract}

Contudo, o aumento das rivalidades (ou, talvez, a maior exploração retórica dessas rivalidades por parte do presidente Donald Trump) não nos autoriza a afirmar que o mundo já tenha retornado à bipolaridade ou a multipolaridade. A citação da China e da Rússia nos documentos oficiais estadunidenses significa que esses países são percebidos pelos EUA como potenciais oponentes. Percepção sobre ameaças é uma variável importante na análise de comportamentos estatais e de desdobramentos internacionais, mas não é uma variável adequada para pensar polaridade sistêmica. Ameaças de segurança podem advir, inclusive, de atores não-estatais como as organizações terroristas. Em outras palavras, China e Rússia são potenciais ameaças de segurança aos EUA, mas ainda não são polos no sistema.

Uma contribuição interessante sobre esse tema advém do Realismo Neoclássico. Nos termos dessa teoria, a polaridade sistêmica (definida pela distribuição de poder relativo entre os Estados mais poderosos do sistema) é variável independente, atuando sobre o comportamento dos Estados (variável dependente). A seu turno, a percepção sobre ameaças (por parte dos tomadores de decisão) funciona como variável interveniente, filtrando os efeitos da polaridade sistêmica sobre o comportamento estatal. Assim, a percepção de rivalidade não define a polaridade sistêmica, mas ajuda, obviamente, a entender o relacionamento dos EUA com a Rússia e a China.

Por outro lado, sobre as tendências de transformação sistêmicas, a meu ver, a China é o Estado que possui maior probabilidade de se tornar um polo no sistema internacional contemporâneo, na medida em que detém considerável poder econômico e apresenta o segundo maior orçamento de defesa do mundo, atrás apenas dos EUA. A ascensão definitiva ao posto de polo dependerá da manutenção do dinamismo econômico chinês, e do aprofundamento dos esforços de modernização das forças armadas, o qual está atrelado, especialmente, ao aprimoramento das capacidades relacionadas à inovação tecnológica na arena militar.

IA - O confronto comercial entre Estados Unidos e China é um dos traços característicos dos tempos atuais. $O$ unilateralismo e a política comercial - agressiva - de Trump é alvo de críticas intensas por parte dos analistas. Por exemplo, Trump quer impor tarifas de $\mathbf{2 5 \%}$ sobre a importação de carros. Como avalia a política comercial de Trump e as consequências dessas para o mundo?

\footnotetext{
${ }^{6}$ Para mais informações, ver: https://www.whitehouse.gov/wp-content/uploads/2017/12/NSS-Final-12-18-2017-0905.pdf.
} 
LD - A relação entre hegemonia e livre-comércio é uma questão bastante debatida por várias das teorias de Relações Internacionais. Para a teoria da estabilidade hegemônica, por exemplo, a aceitação do poder do hegêmona por parte dos demais Estados do sistema não decorre apenas da sua reputação de poder, mas também da sua capacidade de provisão de bens públicos. Nesse sentido, um dos bens públicos tradicionalmente fornecidos pela hegemonia estadunidense foi o livre-comércio. A garantia da livre circulação de bens e mercadorias também é ressaltada por teóricos liberais como uma atividade relacionada à hegemonia ${ }^{7}$.

Não obstante, há autores que discordam da ideia de que a manutenção de tarifas comerciais baixas seja automaticamente do interesse do hegêmona ${ }^{8}$. Isso porque a política comercial atua, muitas vezes, em conjunto com a política de segurança. Na Guerra Fria, a livre circulação de bens, mercadorias e serviços tinha como resultado a provisão de benefícios aos aliados estadunidenses e o fortalecimento das relações com os mesmos. Nesse sentido, eventuais desproporções de ganhos entre os parceiros ocidentais não preocupavam os EUA. Por outro lado, é possível pensar que os déficits comerciais frequentes dos EUA com a China contribuem para o fortalecimento econômico chinês e, consequentemente, para ascensão desse país como pólo no sistema, na medida em que potencialmente financiam a manutenção dos esforços de modernização das forças armadas chinesas.

Não se trata de defender as práticas comerciais agressivas do presidente Donald Trump como moralmente corretas ou como benéficas para os relacionamentos comerciais entre os vários países do globo. Trata-se de enquadrar tais comportamentos no quadro geral da ascensão chinesa e do acirramento das rivalidades entre China e EUA. Se assim o fizermos, creio que a política comercial de Donald Trump (embora seja potencialmente prejudicial a vários países do globo) pode ser qualificada como racional e conforme com os interesses dos EUA na atualidade.

\section{SOBRE A ENTREVISTADA:}

A Prof $\underline{a}$ Dr $\underline{a}$ Layla Dawood possui graduação em Relações Internacionais pela Pontifícia Universidade Católica de Minas Gerais (2005) e gra duação em Direito pela Universidade Federal de Minas Gerais (2006). É mestre em Relações Internacionais pela Pontifícia Universidade Católica de Minas Gerais e doutora em Relações Internacionais pela Pontifícia Universidade Católica do Rio de Janeiro (PUC-Rio). Suas áreas de interesse compreendem a Teoria de Relações Internacionais e a Segurança Internacional, com ênfase nos seguintes temas: política de defesa dos EUA e da China, nãoproliferação nuclear, dissuasão e política nuclear brasileira. Atualmente, é professora adjunta no Departamento de Relações Internacionais da UERJ, Coordenadora Adjunta do Programa de PósGraduação em Relações Internacionais da UERJ (PPGRI) e Secretária Executiva da Associação Brasileira de Relações Internacionais (ABRI).

\footnotetext{
${ }^{7}$ KEOHANE, Robert. After hegemony. Cooperation and discord in the world political economy. Princeton: Princeton University Press, 2005.

${ }^{8}$ Ver: GOWA, Joanne. Hegemonic stability theory: a critical review. In: ton University Press. 1994. p. 11-30. . Allies, adversaries, and international trade. Princeton: Prince-
} 